$8^{\text {th }}$ International Conference on Management, Economics and Humanities

7 - 9 December, 2018

Barcelona, Spain

\title{
Enterprise Training and Business Performance: A Case of Small Business Manufacturing Sector in the West Midlands
}

\author{
Dr. Fahad Sultan \\ Abdul Wali Khan University Mardan, Pakistan
}

The provision of education and training are improving the business performance, which is considered to be a resilient elucidation in bridging workforce skills needs. The small businesses play is the important role, Essential study investigates that how effect performance through the provision of training. The purpose of this research is to examine the impact of education and training on employee's turnover rate; to explore the perception of training amongst owners/managers in education and training, with a particular focus in the West Midlands. Several studies have investigated the importance of education and training in SMEs in developing countries (see, for example, Jones at all., 2013; Panagiotakopoulos, 2011a; Long et al., 2014) have been conducted in the emerging economies. Moreover, the work of (Panagiotakopoulos, 2011a; Storey, 2002, 2004, 2008; Subhan et al., 2013; Thang et al., 2010) have found significance of education and training in improving the employee's turnover rate and business performance to minimize failure. The current knowledge state that they steered of provision training is the previous research that is the developed economy, which is the impact of the small business performance. This exploratory study is related to survey questionnaires including review case study on a mixed-method approach. The semi structured interviews are the choice of case study method which is appropriate order of the researcher and considering the in-depth of finding. For the quantitative research, having the part of survey strategy which can help to get numeric finding accurate. Therefore, this research based in west midlands which on face- to- face interviews 26 semi structure and 136 survey questionnaire within carried out small organization. The sample is taken from the manufacturing sector furniture and food with 9 to 49 the number of employees ranging. The study shows that the results of owners/managers which could enhance the quality of the training and aware that important companies which products are reputable. There is overwhelming evidence of overall business performance, which training positively and the firms' are responding when employees are impacted turnover rate. This study demonstrates that the international competitions are exposed small enterprises; in many cases their products and services are competing across regions, Due to the presence of the global internet, and purchases online. Small enterprises have to remain pertinent and competitive and embrace the internalize training. The research suggests that small business management should find the importance of training and recognize the turnover rate. Training program identifies management needs, training needs and develop a bespoke to demand led training development. International competition is exposed SMEs; In many cases their products and services have competed globally and across the regions. In this research have demonstrated 
$8^{\text {th }}$ International Conference on Management, Economics and Humanities

7 - 9 December, 2018

Barcelona, Spain

result that SMEs have to embrace and internalized training and education to remain relevant and

competitive. The research findings corroborate with the findings of Thang et al. (2010), noted training as a practical activity to improve business performance, involving formal or informal education and training interventions. Enhanced the human resource are a good communication for the business quality of the product. Technical and small business are enabled for the training to use technology efficiently and how to know re-invent owner/managers to remain product competitive.

Key words: Enterprise Training, Small business, Performance, Employee's Turnover rate, West Midlands, United Kingdom.

\section{Introduction:}

(Dai, 2012) Small businesses are being the original competitiveness, through learning innovative and efficient. Small business for training is depending on the system which are belief of owner, sharing of knowledge are clearly the way of the environment to enable learning to take place and the support systems of a place (Renta-Davids et al., 2014). UK like the infrastructure economies developed have to invested the small businesses which are engage with trand and enable the training are supported by recent research which the research suggests that the training, retention work environment has a positive effect on a firms', which has effective knowledge acquisition (Ellinger et al., 2011; Lancaster and Di Milia, 2014). The aim of the research study to examine how to impact organizational training on employees' turnover rate and overall performance firms'. The topic is explored within a specific context in the West Midlands ${ }^{1}$ area of small business furniture and food manufacturing units.

\section{Definition: Small Businesses:}

The particularity of UK, USA or Europe, there is no uniform definition of the worldwide literature across the small businesses. The researcher definition of training small businesses' size varies from one country to another country, the total assets of the revenues are classified of items are the number of employees. However, Malik and Nilakant (2011) suggest that the general problematic definitions are the number of employee's which based on the assets and revenues. In the first case that the further explanation which are the historical asset value and the crucial point, which can be used of high inflation at a time, which about the India and chain. Secondly, definition does not fit the revenues for domestic small business unit which suited threshold with lower revenues particularly developed, developed economy are emerging. Thirdly, the researcher defines that the different scales to measure the countries are adopting of SMEs for the number of employee's. The researcher defines the small business may also vary with different regions, even from one industry to another industry and within a country or state (Gilaninia et al., 2011). In the definition of small business pursuit of Hallberg (2000) and Upadhyay (2007) in argue that the consensus is not practicable and neither

\footnotetext{
${ }^{1}$ Metropolitan County in western central England contains six districts, Birmingham, Sandwell, Dudley, Walsall, Wolverhampton and Solihull.
} 
$8^{\text {th }}$ International Conference on Management, Economics and Humanities

7 - 9 December, 2018

Barcelona, Spain

possible where we have in socio-economic are diversity of small business environments. ElGohary (2010), argue that there is always SMEs limited agreement on the definition are practitioners and between the government agencies.

The case of the above discussions, are the available approach to define best recent empirical studies suggest that the small business organizations and the number of employees should be calculated of paid (Paik et al, 2011; Bauchet and Morduch, 2013). Thus, within the small business organization is pointed out and the definition of the research is basis of workforce preferred is paid is to balance sheet of a comparison based, but assets are the small business manipulation which openly subjective of the valuations. The researcher defines that they employ are based on the number of employees as shown in the table below. The Table 1 are official demonstrates (or the most commonly used) that the definition are size of items, total assets of the employee and total annual sales of Micro, Small and Medium size of Organizations (MSME) which are used in development, in emerging the developing economies. 
Humanities

Barcelona, Spain

Table 1: Definition of Developing Economy and Emerging, SMEs in Developed

\begin{tabular}{|c|c|c|c|c|c|}
\hline Country & Size & Employees & Total assets & Total annual Sales & Other \\
\hline \multirow[t]{4}{*}{ USA } & & & & & \\
\hline & Micro & $<10$ & $<\$ 100,000$ & $<\$ 100,000$ & None \\
\hline & Small & $10<50$ & $<\$ 100,000<\$ 3$ million & $<\$ 100,000<\$ 3$ million & None \\
\hline & Medium & $50<300$ & $<\$ 3$ million $<\$ 15$ million & $<\$ 3$ million $<\$ 15$ million & None \\
\hline \multirow[t]{3}{*}{ UK } & Micro & $<10$ & $<£ 1.2$ million & $<£ 1.2$ million & \multirow[t]{3}{*}{ None } \\
\hline & Small & $10<49$ & $<£ 6.5$ million & $<£ 6.5$ million & \\
\hline & Medium & $50<249$ & $<£ 25.9$ million & $<£ 25.9$ million & \\
\hline \multirow[t]{2}{*}{ European commission } & Micro & $<10$ & $<€ 2$ million & $<€ 2$ million & None \\
\hline & Small & $10<49$ & $<€ 10$ million & $<€ 10$ million & $\begin{array}{c}\text { Balance sheet total } \\
\text { less than } € 10 \\
\text { million }\end{array}$ \\
\hline
\end{tabular}




\begin{tabular}{|c|c|c|c|c|c|}
\hline & Medium & $50<250$ & $<€ 43$ million & $<€ 50$ million & $\begin{array}{c}\text { Balance sheet total } \\
\text { less than } € 43 \\
\text { million }\end{array}$ \\
\hline \multirow[t]{3}{*}{ Malaysia } & Micro & $<5$ & $<\mathrm{RM} 250 \mathrm{~K}$ & $<$ RM250K & \multirow[t]{3}{*}{ None } \\
\hline & Small & $5<50$ & $<$ RM10million & $<$ RM10million & \\
\hline & Medium & $50<150$ & $<$ RM50million & $<$ RM50million & \\
\hline \multirow[t]{3}{*}{ Indonesia } & Micro & $<5$ & $<50$ million & $<5$ million & \multirow[t]{3}{*}{ None } \\
\hline & Small & $5<19$ & $<200$ million & <RP1billion & \\
\hline & Medium & $20<99$ & $<10$ billion & $<$ RP1billion & \\
\hline Turkey & Micro & $<10$ & $<€ 2$ million & $<€ 2$ million & None \\
\hline
\end{tabular}

8th International Conference on Management, Economics

Humanities

\begin{tabular}{|c|c|c|c|c|c|}
\hline & \multicolumn{2}{|c|}{7 - 9 December, 2018} & \multicolumn{2}{|c|}{ Barcelona, Spain } & \\
\hline & Small & $10<49$ & $<€ 10$ million & $<€ 10$ million & \\
\hline & Medium & $50<250$ & $<€ 43$ million & $<€ 50$ million & \\
\hline \multirow[t]{3}{*}{ Pakistan } & \multirow[t]{2}{*}{ Small } & \multirow[t]{2}{*}{$10<49$} & PKR 5million & None & \multirow[t]{3}{*}{ None } \\
\hline & & & PKR 25million & None & \\
\hline & Medium & $50<250$ & & & \\
\hline
\end{tabular}

Source: Syed et al. (2015). 
8 
$8^{\text {th }}$ International Conference on Management, Economics and Humanities

7 - 9 December, 2018

Barcelona, Spain

\section{Statistics of Small Businesses:}

In Europe (Lazanyi, 2015), there are 22.3 million SMEs, in the UK based are 5.4 million (DBIS, 2015). (0-249) small or medium size businesses, 99.9 percent of businesses are micro, employing 15.6 million people are According to DBIS (2015),. 62.6 percent businesses are sole trader business, 18 percent by the females owner In the UK, (Telegraph, 2014). (DBIS, 2015) argues that Within 5.3 million or small business of micro, 5.4 million SMEs in the country, the total SMEs market share constituting 99.3 percent. In the year 2015 of employee annual turnover is combined $f 1.8$ trillion, with 24.3 million (HOC, 2015). There is a total of 400,000 SMEs of the West Midland, in the region 106,000 employed people (EIB, 2015). The only 5 percent area is covered by the manufacturing sector and the total population of SMEs in the region of West Midlands, however, the number of SMEs is significantly low (HOC, 2015). The past few decades the significantly lower number of manufacturing SMEs confirms and it was dominated by small firms that the manufacturing sector has been severely affected (SEV, 2010). Therefore, in the UK case, the prime focus of the area of West Midlands will be the research investigation.

\section{Problem Statement and Research Context:}

(Autio et al., 2014; Wang et al., 2012) suggest that the policy makers and practitioners, academics have in interested long been and providing explanations for changes in the national system of skills formation. All small businesses as the importance of skilled it is becoming increasingly SMEs and ignore the difficult workforce and adaptable (Demirbas et al., 2011). During the recent years, governments are emerging the developing economy which is a high level of priority on training and to encourage the education innovation. (Sikka, 2008), argue that the developed countries his is particularly noticeable where the promoting government is focused 'enterprise culture' In the researcher give an example of the UK and US (Athayde, 2012). Is reported to be emerging is a similar trend within economies emerging (Matlay, 2009). The entrepreneurship training is considered to be the prevailing mode of enterprise vitality and economic growth to promote an entrepreneurial culture (Alberti et al., 2008). Organization for Economic Co-operation and Development (OECD) considers employment training and education to promote essential economic cohesion and economic growth, within world economies. The Researcher examine that the governance infrastructure positively impact upon the Enterprise Education (EE), and institutions in any economy (Lattimore and Love, 2009).

The world economy needs to promote the education and training and it has been reported that the convergence has drawn Knowledge Management (KM) and Enterprise Education (EE) and its focus of a small firm sharper at has same time and have needs the intellectual capital of heightened (Becker, 1962; Khalique et al., 2015), SMEs (Arthur et al., 2012) human resources training and development, these are significantly interrelated with business performance. Pozas and Jauregui (2012) argue that the training and business performance are intertwined with an employment level, skills, human capital, and overall growth in Gross Domestic Product (GDP). The competitiveness of any business, regardless of the West Midlands, to be essential size of business most owners consider the trained and skilled 
$8^{\text {th }}$ International Conference on Management, Economics and Humanities

7 - 9 December, 2018

Barcelona, Spain

workers (Samra, 2009). However, the enough resources (financial and non financial) are mostly supported large firms this view is more willing to be their personal compared of trained, smaller counterparts who tend to lack of infrastructure resources, time access to provision training (Sultan et al., 2016).

The survival of an organization practice as a basic and significant has been advocated for every training and job (Garavan, 2007). The intellectual capital is progressive SMEs have been found the training and development against their competitors practice to place emphasis upon as a competitive weapon (Samra, 2009). The concept of raising the entire discipline of Central SMEs is the capacity of human resource in the business. The prior research has exist evidence which is the active provision, has a higher training Return On Sales (ROS) Return On Investment (ROI), and Return On Assets (ROA) in any economy of production (Thang and Quang, 2011; Manimala and Kuamr, 2012). In these study the non-financial performance context, according to the researcher by Becker presented Human Capital Theory (HCT) (Becker, 1962, 1964, 1993) improve the small business training of Knowledge, Skills and Abilities (KSAs) to enhanced the employees leading business performance (Manimala and Kumar, 2012). The researcher (Beynon et al, 2015; Malik and Nilakant, 2011) has been acknowledged that the training of employee has an impact on turnover rate of retention (Khan et al, 2013; UKCES, 2012) the small business reducing the motivation errors of employee's (Diamantidis and Chatzoglou, 2012) and increase business performance. The researcher argues that the small business employees are well skilled workers have a positive impact on training for success and productivity (Lambert et al., 2007). The researcher vein, Zheng et al. (2006) suggest that training is reducing the turnover rate in small firms assist in maintaining employees' commitment. However, Sultan et al. (2016) by critiqued has been the latter point, that the researcher examine that training enterprise does not have any relationship direct or indirect link of employees or employee and maintaining the turnover rate and reducing the job performance. Panagiotakopoulos (2011) and Sultan et al. (2016) the researcher suggest that the given present information very scant and fail to any significant evidence of the employees turnover rate.

Hussain and Matlay, (2007) the West Midland use semi- structured interview with a small firm located in the interviewed by the 66 owners /managers, which they associated with the distinguished concepts of SMEs of managers' perceptions in the training. An existing relationship between business performance an individual' training, which is dependent the discretion totally on management ( $\mathrm{Nel}$ and Simpson, 2011; Rosli and Sidek, 2013). To invest in training reluctant is a small business from a management perspective (Hashim and Wok, 2013). Approaches method does attract many owners of small business to compete the skilled workers, rather than the small business is invest in the training (Knudsen and Lien, 2015). This approach method is used by the Market Signalling Theory (MST) which is presented by the Spence (1973) where the focus in the workforce is marketability.

The concept of Market Signalling Theory (MST) based on the Human Capital Theory (HCT), in the external labour market hinges assumptions that within SMEs mainly marketability has a 
$8^{\text {th }}$ International Conference on Management, Economics and Humanities

7 - 9 December, 2018

Barcelona, Spain

higher skilled workforce (Sarapaivanich and Patterson, 2015). Market Signalling Theory (MST) Haines et al. (2010) enhances the' workforce is the external marketability, which has a significant relationship of small business with the SMEs of employees turnover rate. The researcher explore the significantly associated employee's training which is supported by recent studies of small business and leads of the empirical poaching of employees turnover rate (Abed Rahman et al., 2013; Rouditser and McKeown, 2015). However, Spence (1973) Market Signalling Theory (MST) explain that the unintended provision impact of training is linked with Human Capital Skills (HCS) and has an external marketability.

Loveridge and Mok (2012), explore that the imperfection of the internal and external market issue could be related to the external SMEsI marketability, which is associated with the provision of significantly small business training. Ahmed and Chowdhury (2009) suggest that the lack of resource with a skilled workforce are point out in the shortage of External Labour Market (ELM) in training exist Internal Labour Market (ILM) issues for emerging economies. Leitch (2006) In the case of the UK, a distinctive attention draws our prediction attention that by 2020,70 percent more than the UK population will access training not able, which is a policy maker for the challenge. Lee (2014) supports that that in the particular countries OEC in the parts of the UK, Leitch (2006) and argues that the skilled workforce is a recruitment for performance of growth is the existing staff of shortage are the key hindrance in SMEs'. However, the effectiveness of SMEs, within the formal and informal provision of training (FSB, $2009,2013)$, the rewards and compensation, performance based could improve the system of scenario (McEvoy and Buller, 2013).

\section{Research Methodology}

The purpose of this study is twofold. In these research methodology is the first phase, the case study is qualitative approach was "how' and 'why' adopted to the questions and the answers to test the relationship between the SMEs and relate the performance of training. The researcher use of qualitative approach techniques which is the basis of real life contexts and justified on the gather data about phenomena through conducting interviews (Supino and Borer, 2012). These research suggest that the training and performance is the phenomenon is the relationship of small business sectors. Robust in-depth is the phenomenon of examination is the second phase of research methodology which is needed to address the research questions and generate hypotheses. This study is supported by Guba and Lincoln (1994) approach who suggested that the research methodology or other social science, to investigate the effective ways of hypothesis development is a more natural setting and the research questions, finding as an inquiry of present elements. The researcher further argue of the research which is very useful and helpful development of hypothesis to explore the case are effective that the post-positivism relationship approach is the adoption of emphasizes (Lincoln and Guba, 2000). Therefore, small business organizations were considered is more less than 49 and more than 9 as a control variable of employees.

This study conducts the parts of qualitative semi structured interview of owners/manger/employees with the 26 small firms. Panagiotakopoulos (2011a) suggested that "a researcher's gain the ability in-depth, they ask a limit question a uniform knowledge 
$8^{\text {th }}$ International Conference on Management, Economics and Humanities

7 - 9 December, 2018

Barcelona, Spain

of structured approaches tend to add worth whereas understanding of the issue,greater opportunity to explore the time consuming though the issue in-depth". According to Saunders et al. (2009), semi-structured or open ended interview technique is useful questions when additional may be required to explore the emerging issues that understanding of the nature events may help to gain within a particular organization. Exploratory or explanatory study provides the Semi structured interviews when undertaking in-depth results. However, it is an important designing of interviews and semi-structured questionnaires which are considered as reliability such as a key issue, the validity of the finding is the form of bias which can be the impact of the result. For this purpose, purposive is nonprobability sampling perhaps is the best investigate of the related training-performance choices. The research topic can be also used for the best getting information by the selecting items or as a way of people most likely to provide the quality of information the experience or expertise valuable insights (Yin, 2012). In this way the researcher used, a research model is particularly well suited for developing of purposive sampling (Denscombe, 2010). Hussain et al. (2011) by are used approach and Saunders et al. (2012) is recommended all recorded interview were transcribed and are taken from possible additional notes, for completeness and accuracy's sake.

For explanatory and descriptive research, a key data collection method can be used as a questionnaire to investigate attitude, a key data collection can be used as a questionnaire method to investigate attitude, examine are the relationship between the opinion variables, the cause-and-effect relationship especially to identify the choice of content (Saunders et al., 2012; Yin, 2012). However, the questionnaire's size was designed, and type of sample is strongly related to the research questions and research objectives. A Questionnaire was designed by the different types of questions, self-administrated (delivery and collection) to responses to collect the key research questions. In this research, was asked the 136 survey questionnaires. Closed ended Questionnaires in these researches, this questionnaire were clearly written, but the more person effort was made and avoided the complexity and ensure sequenced was careful to ensure they interest the retained of the respondent. The studies should aim to obtain a minimum response are often observed and in the observation made by Saunders et al. (2009) for quantitative rate studies between 30-50 Percent. For this purpose, stratified sampling technique was adopted, the sampling error is minimized applying the probability sampling techniques. In the West Midland region manufacturing companies in the identified from the sector database, the trade association is the local chamber of commerce.

\section{Results and discussion}

\section{Semi Structured interviews Analysis and Discussion}

The main purpose of this study is twofold. The first highlights categories of description, data analysis and discussion for 26 interviews conducted within the small business organizations in 
$8^{\text {th }}$ International Conference on Management, Economics and Humanities

7 - 9 December, 2018

Barcelona, Spain

the West Midlands. The researcher gain to enable approach for a small business training of better understanding to related activities of SMEs performance and training. The variations description of categories was also established by the owner/managers in focusing the training practices of small organizations, impact on the employee's turnover rate. The small business notions of commitment are used of the employee's turnover rate as training practices are independent variable as a dependent variable are (on the job, off the job, formal, informal, general, apprenticeship). A number of concerns and characteristic regarding the analysis of the data environment in the training reveals which has been certain fluctuates identified of employee turnover rate. As a small business training is explained:

... "Formal or informal training have an obvious dose impact on the overall business performance and employee's turnover rate. However, the employees varies are the small business which is dependent sector to sector and industry to industry. The first key element is the employee is commitment and loyalty of any the organization. Training is a time being for the human resource enhance the commitment or loyalty, however, training are not important because the wages and other relevant benefits are more concerned with the employees of small business. The Second key element is absolutely ethical which competition for workforce skills. However, the management use poaching methods to attain skilled workforce". (UK).

Two key elements are identified analysis of the semi-structured interviews. Firstly, a small business is reactive nature, a positive relationship has been causal, the human resources development between training and employee turnover rate. Therefore, the key driving are forces of career progression, compensation and benefits. This research is consistent with the most recent study small business which is conducted by Beynon et al (2015) in Wales. This research study adopts a significant novel analysis technique, which showing positive relationships between commitment and training of employees (Beynon et al., 2015). However, direct and indirect various can be affected by market forces as well as personal and psychological characteristics (Giauque et al., 2010). According to Hasnnon (2009), the training of benefits is not confined to financial incentives and career progression only, the employability of the recipient is also the development of training, and the commitment can also to encourage of the organization. However, the present study of the trend findings reveals that employees are more committed and loyal only when there is a link between career progression, training provision, and an increase the employees' wages. Therefore, in these researches assume that the logical, of the small business has directed, trained proportional to the investment of employees' commitment and loyalty; in this research the employees see a significant positive relationship with the increase in wages (Malik and Nilakant, 2011) and in career progression (Hasnnon, 2009) then the internal and external training are more likely to participate. Secondly, it is worth noting that the employees of poaching implication by the external management responses are the firms. Small business is owners of training as the threat of an immediate in respect of employee loss and loss of financial. This research view with the Market Signalling Theory (MST) proposed by Spence (1973) that the training of human resource has the external consequences unintended of marketability is increasing. In the small business conventional environment, is the domestic market lead of the MST 
$8^{\text {th }}$ International Conference on Management, Economics and Humanities

7 - 9 December, 2018

Barcelona, Spain

approach which increase demand level for a workforce skilled. To compete with management for a workforce skilled which prefer small business rather than the employee invest in training. Unfortunately, the workforce skilled imperfections in the labour market and capital market of developing economies encourage to peach small business management. Small business general manager in the same manner of a food unit manufacturing is explained:

... "In the current local market, a skilled workforce is to find very difficult run operational activity. Formal approaches are reducing the employee's turnover rate and effective for the long term. However, the time consuming is too expensive. Therefore, we prefer to provide training on the job, with limited resources preferably apprenticeships". (UK). 


\section{Table 2: Descriptive Information about Small Businesses}

\begin{tabular}{|c|c|c|c|c|c|c|c|c|c|c|c|c|c|c|c|c|c|c|c|c|c|c|c|c|c|c|}
\hline \multicolumn{27}{|c|}{ List of Semi Structured Interviews } \\
\hline $\begin{array}{l}\text { Number } \\
\mathrm{S}\end{array}$ & 1 & 2 & 3 & 4 & 5 & 6 & 7 & 8 & 9 & 10 & 11 & 12 & 13 & 14 & 15 & 16 & 17 & 18 & 19 & 20 & 21 & 22 & 23 & 24 & 25 & 26 \\
\hline $\begin{array}{l}\text { Firms' } \\
\text { Code }\end{array}$ & \multicolumn{26}{|c|}{ UK1, UK2, UK3, UK4, UK5, UK66 } \\
\hline $\begin{array}{l}\text { Particip } \\
\text { ants } \\
\text { Code }\end{array}$ & \multicolumn{26}{|c|}{$\begin{array}{l}\text { UKa1, UKa2, UKa3, UKa4, UKa5, UKa6, UKa7, UKa8, UKa9, UKa10, UKa11, UKa12, UKa13, UKa14, UKa15, UKa16, UKa17, UKa18, UKa19 } \\
\text { UKa20, UKa21, UKa22, UKa23, UKa24, UKa25, UKa26 }\end{array}$} \\
\hline Size & 11 & 32 & 19 & 13 & 27 & 33 & 44 & 48 & 36 & 12 & 23 & 35 & 17 & 19 & 16 & 14 & 10 & 14 & 21 & 28 & 20 & 18 & 21 & 24 & 32 & 12 \\
\hline Location & B & S1 & B & $\mathrm{D}$ & $\begin{array}{l}W \\
1\end{array}$ & $\begin{array}{l}W \\
2\end{array}$ & $\mathrm{~S} 2$ & S2 & B & S1 & S1 & $\mathrm{D}$ & $\mathrm{D}$ & D & $\begin{array}{l}W \\
1\end{array}$ & $\begin{array}{l}W \\
1\end{array}$ & $\begin{array}{l}W \\
2\end{array}$ & $\begin{array}{l}W \\
2\end{array}$ & $\begin{array}{l}W \\
2\end{array}$ & B & B & B & S2 & B & $\mathrm{D}$ & B \\
\hline $\begin{array}{l}\text { Owners } \\
\text { hip }\end{array}$ & SP & $P$ & SP & SP & SP & $P$ & $\mathrm{P}$ & $P$ & $\mathrm{P}$ & SP & $P$ & $\mathrm{P}$ & SP & SP & SP & $P$ & SP & SP & $\mathrm{P}$ & $\mathrm{P}$ & $P$ & SP & SP & SP & $P$ & SP \\
\hline $\begin{array}{l}\text { Educati } \\
\text { on }\end{array}$ & $\begin{array}{l}M \\
S\end{array}$ & $\begin{array}{l}M \\
S\end{array}$ & HS & HS & HS & $\mathrm{HS}$ & $\mathrm{HS}$ & $\begin{array}{l}C \\
G\end{array}$ & HS & $\mathrm{HS}$ & $\begin{array}{l}\mathrm{C} \\
\mathrm{G}\end{array}$ & HS & $\begin{array}{l}C \\
G\end{array}$ & $\begin{array}{l}C \\
\text { G }\end{array}$ & HS & $\begin{array}{l}M \\
S\end{array}$ & $\begin{array}{l}M \\
S\end{array}$ & $\begin{array}{l}M \\
S\end{array}$ & $\begin{array}{l}U \\
G\end{array}$ & $\begin{array}{l}\mathrm{C} \\
\mathrm{G}\end{array}$ & $\begin{array}{l}C \\
G\end{array}$ & HS & CG & HS & CG & HS \\
\hline $\begin{array}{l}\text { Age o of } \\
\text { business }\end{array}$ & 7 & 12 & 6 & 8 & 16 & 11 & 18 & 14 & 15 & 5 & 7 & 9 & 10 & 11 & 14 & 9 & 6 & 5 & 12 & 16 & 11 & 10 & 6 & 17 & 14 & 8 \\
\hline Gender & $M$ & $M$ & $M$ & $M$ & $M$ & $M$ & $M$ & $M$ & $M$ & $M$ & $M$ & $M$ & $M$ & $M$ & $M$ & $M$ & $M$ & $M$ & $M$ & $M$ & $M$ & $M$ & $M$ & $M$ & $M$ & $M$ \\
\hline
\end{tabular}

Note: UKa1=Owner, UKa2=Manager, UKa3=Manager, UKa4=Owners. UKa5=Owner, UKa6=Owner, UKa7=Manager.UKa8=Owner, UKa9=Owner, 
UKa10=Manager, UKa11=Manager,

UKa12= Owner. UKa13=Owner, UKa14=Owner, UKa15=Owner, UKa16=Manager, UKa17=Manager. UKa18=Owner, UKa19=Manager, UKa20=Manager. UKa21=Owner,

UKa22=Owner, UKa23=Manager, UKa24=Manager. UKa25=Owner, UKa26=Owner,

$\mathrm{SP}=$ Sole proprietorship, $\mathrm{P}=$ Partnership

$\mathrm{MS}=$ Middle school, $\mathrm{HS}=$ High school, $\mathrm{CG}=$ College graduate, $\mathrm{UG}=$ University graduate $\mathrm{M}=$ Male. $\mathrm{F}=$ Female

West Midlands= Birmingham, Sandwell, Dudley, Walsall, Wolverhampton and Solihull

$\mathrm{B}=$ Birmingham, $\mathrm{S} 1=$ Sandwell, S2= Solihull, W1= Wolverhampton, W2= Walsall, D= Dudley

\section{Table 3. Breakdown of coding criteria for Enterprise training}

\begin{tabular}{|c|c|c|c|}
\hline No & Theoretical criteria & Information & Coding types \\
\hline 1 & Education & Any VET or other education & School, college, university, VET Institute \\
\hline 2 & Experience & Total experience & Less than 5 years, 5 or more years, 10 or more \\
\hline 3 & $\begin{array}{l}\text { Time of } \\
\text { employment }\end{array}$ & Time with current employer & Less than 5 years, 5 years or more, 10 years or more \\
\hline 4 & Type of SME & Number of workforce & Small \\
\hline 5 & Sectorial approach & Manufacturing & Manufacturing \\
\hline 6 & Business type & Furniture manufacturing & Furniture Manufacturing \\
\hline
\end{tabular}




\begin{tabular}{|c|c|c|c|}
\hline 7 & Location & Physical location & Urban \\
\hline 8 & Ownership & Type of business ownership & Sole proprietorship , Partnership \\
\hline 9 & Age & Age of the particular business & 5 years or more, 10 years or more \\
\hline 10 & Employment type & Nature of the employment & Full time, Part time \\
\hline 11 & Training barriers & $\begin{array}{l}\text { Demand and supply of training are } \\
\text { relating barriers }\end{array}$ & $\begin{array}{l}\text { Political, economic, social, legal, organisational, } \\
\text { technological, environmental }\end{array}$ \\
\hline 12 & Training practices & Different types of training practices & Formal/Informal, On the job/ Off the job \\
\hline 13 & Techniques & $\begin{array}{l}\text { Suitable techniques for small business } \\
\text { training }\end{array}$ & $\begin{array}{l}\text { Outside courses, Internal training with own resources, } \\
\text { Universities/colleges/VET, Coaching/apprenticeship, ad-hoc, job } \\
\text { rotation, ad-hoc }\end{array}$ \\
\hline 14 & Category of training & External training or main type of in house & Management training, Technology based, General training/KSAs, Other \\
\hline 15 & $\begin{array}{l}\text { Training } \\
\text { performance } \\
\text { relationship }\end{array}$ & $\begin{array}{l}\text { Impact of training on the performance of } \\
\text { business }\end{array}$ & Improve KSAs, growth, General performance \\
\hline 16 & Period & Training period & Frequently, Rare, Never, Induction only \\
\hline 17 & $\begin{array}{l}\text { Government } \\
\text { polices }\end{array}$ & 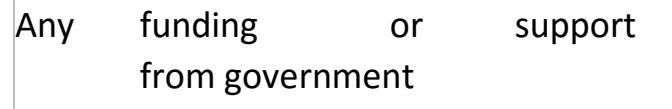 & Loans, Training, Assistance, Contract schemes, incentives, None \\
\hline
\end{tabular}

Design by researcher 
The view that informal small business training is respondents invariably support (apprenticeship preferably) which is associated over training practices with small business performance. Therefore, the importance of formal methods is the acknowledged of UK manager, but also found a lack of financial and non financial resources which is not feasible of small business. The behavior model with Such findings in line which is presented by Schuler and Jackson (1987). The training invests a reluctant of small business management, however, in the successful manufacturing sector with the implementation of the behavioral model approach (Thang et al., 2010). The appropriateness to the adoption model Human Capital Theory (HCT) involving all hierarchal layers within SMSs (management and employees), within a hierarchal layer of the significant impact of training to reduce the employee turnover rate and can enhancement lead of both individual business performance.

\section{Multiple Regression Analysis and Discussion}

The impact of training to investigate on small business performance, Multiple Regression Analysis (MRA) allows us to test the Models and find the impact of several Independent Variables (IVs) on single Dependent Variables (DV). This technique is consistent with previous empirical studies, for example (Jayawarna et al., 2007; Macpherson and Jayawarna, 2007) to investigate the impact of training on small business performance. To predict the value of Dependent Variables (DV) performance based on the value of Independent Variables (IVs) training approaches the following formula was designed for the Multiple Linear Regression Equation (MLRE):

$$
y=b 0+b 1 x 1+b 2 x 2 \ldots \ldots+b k x k+\varepsilon
$$

In the case of training-performance relationship:

$Y \quad$ designated as the dependent variable bo the $y$ intercept, the value of $y$ when all $X s=0$

$X \quad$ designated as the independent variable

b1...k the various coefficients assigned to the independent variables $\varepsilon$ the standard error of the estimates.

In the above mentioned equation are the regression coefficient ( $\beta$ )of a non-random and standard error of estimates $(\varepsilon)$ is the random. Draper and Smith (2014) argue that the values of ' $y$ ' (dependent variable) allow calculating regression coefficients (6). Similarly, the researcher explains the correlation coefficient of magnitude and direction of two variables. According to (Nathans et al., 2012), correlation coefficient reflects the value of one variable is reflected on the other value of a variable which predicts changes. This means in the case of Positive Correlation (PC) the values of variables increase or decrease in tandem. However, in the event of Negative Correlation (NC), if the predicted value of one variable increases their other value goes down simultaneously. Moreover, to test the Null Hypothesis $\left(\mathrm{H}_{0}\right)$, the statistical method ANOVA is used to check the relationship between Dependent Variable (DV) and Independent Variables (IVs). For this purpose using ANOVA, the $F$ ratio ( $F$ test) is adopted to analyze the significance of the regression $\operatorname{Model}(R)$, to confirm the significance at the 0.05 
$8^{\text {th }}$ International Conference on Management, Economics and Humanities

7 - 9 December, 2018

Barcelona, Spain

levels or better. Multiple Regression Analysis (MRA) can be explained by Multiple linear Regression Equation (MLRE) to identify the impact of training on small business performance, as follows:

Small business employees' turnover rate $=$ Constant $+\beta_{1}$ Formal training $\mathrm{H} 1.2(\mathrm{H} 1.1 .1 \mathrm{UK}$ and $\mathrm{H} 1.2 .1 \mathrm{PAK})+\beta_{2}$ Informal training $\mathrm{H} 1.1(\mathrm{H} 1.1 .2 \mathrm{UK}$ and $\mathrm{H} 1.1 .2 \mathrm{PAK})+\beta_{3}$ General training $\mathrm{H} 1.1$ (H1.1.3UK and H1.1.3PAK) $+\beta_{4}$ Apprenticeship training $\mathrm{H} 1.1$ (H1.1.4UK and H1.1.4PAK)+ $\beta_{5} \mathrm{Off}$ the job training $\mathrm{H} 1.1$ (H1.1.5UK and H1.1.5PAK) $+\beta_{6}$ On the job training $\mathrm{H} 1.1$ (H1.1. 6UK and $\mathrm{H}$ 1.1.6PAK) $+\varepsilon$.

To investigate each of the hypotheses, all the Indenpent Variables (IVs) related to the trainingperformance relationship were entered into a single block to test the relationship between Independent Variables (IVs) and Dependent Variables (DV). In Model 1, the proposed Multiple Regression Analysis (MRA) shows a significant percentage of variance to indicate the impact of training on small business performance in terms of employees' turnover rates. If we look at the summary of Models 1 , the results show that the observed variability in small business employees' turnover rates are explained by the six IVs $\left(R^{2}=0.916\right.$, Adjusted $R^{2}=$ 0.912) Model 1. According to Pallant (2013), the $R^{2}$ in any model summary confirms how much of the variance in the dependent variable (DV) is explained in each case.

Table 4: Model's Summary

Training practice's impact on Employees' Turnover

\begin{tabular}{|c|c|c|c|c|}
\hline Model & $\mathbf{R}$ & R Square & Adjusted R Square & $\begin{array}{l}\text { Std. Error of the } \\
\text { Estimate }\end{array}$ \\
\hline 1 UK & $.957^{\mathrm{a}}$ & .916 & .912 & .331 \\
\hline
\end{tabular}

In Models 1, the adjusted $R^{2}$ value is 0.912 , which explains the 91.2 percent of variance in the Model. The high value of $R^{2}$ confirms the Norris et al. (2014) argument that the MR model explains the variations in DVs quite well and the values are acceptable. Models 1 also demonstrates the output value of the adjusted R square. According to Blossfeld et al. (2014), the main purpose of the adjusted value is to provide better statistics on the true population value in any particular case. In the next step to assess the statistical significance, ANOVA was used to test the Null Hypothesis $\left(\mathrm{H}_{0}\right)$. It is important to find out that there is no linear relationship among DV (employees' turnover) and the IVs (formal, informal, general, apprenticeship, on the job, off the job, training). Table 5 demonstrates both cases and presents the ANOVA analysis. The results confirm that the ratio of the mean square is 233.921 (Model 1, $\mathrm{F}=233.921, \mathrm{P}<0.001$ ). Furthermore, in Model 1 significance of values less than the .001 , confirms that IVs influences the employee's turnover rate in small business units, see Table 5 below.

Table 5: ANOVA

\begin{tabular}{|l|c|c|c|c|c|}
\hline Models & $\begin{array}{c}\text { Sum of } \\
\text { Squares }\end{array}$ & Df & Mean Square & F & Sig. \\
\hline
\end{tabular}


$8^{\text {th }}$ International Conference on Management, Economics and Humanities

7 - 9 December, 2018

Barcelona, Spain

\begin{tabular}{|c|c|c|c|c|c|c|}
\hline $\mathbf{1}$ UK & $\begin{array}{c}\text { Regressio } \\
\mathrm{n}\end{array}$ & 153.655 & 6 & 25.609 & 233.921 & $\begin{array}{c}.000 \\
\mathrm{~b}\end{array}$ \\
\hline & Residual & 14.123 & 129 & & & \\
\hline & Total & 167.778 & 135 & & & \\
\hline
\end{tabular}

a. Dependent Variable: ETRP

b. Predictors: (Constant), FTA, IFTA, GTA, AppT, OffJT, OnJT

Tables 6 shows that $\mathrm{H}_{0}$ is rejected for Model 1 , based on the partial regression coefficient value which is zero for IFTA ( $B=.433, t=4.261, p<0.001)$, GTA $(B=.275, t=2.775, p<0.05)$, AppT $(B=.801, t=11.404, p<0.001)$, OnJT $(B=.181, t=1.994, p<0.05)$. Models 1 also confirms that multicollinearity between the IVs is minimized. According to Pallant and Manual (2010), a $T$ value of less than 0.10 confirms the existence of multicollinearity. In Model 1 the T value ranges from 0.132 to 0.480 , also confirming that multicollinearity is not an issue between IVs. Similarly, the VIF values range between 2.082 and 7.554 for Model 1. Previous empirical studies (for example, Hair et al., 1995; Kennedy, 1992; Marquardt, 1970) confirm the most common value of VIF is 10 . However, values above 10 are a serious concern for the research and confirm multicollinearity between the indicators (Norris et al., 2014). The Analysis also confirms that for Models 1 , the T value for each IV is not less than 0.10 . Similarly, in the case of VIF, all values are less than 10 confirming the reliability of results in the West Midlands, as shown in Tables 6. However, the FTA ( $B=.030, t=.535, p>0.05)$, and OffJT ( $B=.012, t=0.250$, $p>0.05$ ) in Model 1 do not contribute significantly and demonstrate a 3 percent and 1 percent variance in DV respectively.

\begin{tabular}{|c|c|c|c|c|c|c|c|c|}
\hline \multirow{2}{*}{\multicolumn{2}{|c|}{ Model 1 UK }} & \multicolumn{2}{|c|}{$\begin{array}{l}\text { Unstandardized } \\
\text { Coefficients }\end{array}$} & \multirow{2}{*}{$\begin{array}{c}\text { Standardized } \\
\text { Coefficients } \\
\text { Beta }\end{array}$} & \multirow[t]{2}{*}{$\mathbf{t}$} & \multirow[t]{2}{*}{ Sig. } & \multicolumn{2}{|c|}{ Collinearity Statistics } \\
\hline & & B & $\begin{array}{l}\text { Std. } \\
\text { Error }\end{array}$ & & & & Tolerance & VIF \\
\hline \multirow[t]{7}{*}{1} & $\begin{array}{c}\text { (Constant } \\
\text { ) }\end{array}$ & .246 & .115 & & 2.140 & .034 & & \\
\hline & FTA & .028 & .052 & .030 & 0.535 & .593 & .207 & 4.834 \\
\hline & IFTA & .366 & .039 & .433 & 4.261 & .000 & .318 & 3.144 \\
\hline & GTA & .259 & .067 & .275 & 2.775 & .007 & .480 & 2.082 \\
\hline & AppT & .785 & .069 & .801 & 11.404 & .000 & .132 & 7.554 \\
\hline & OffJT & .012 & .047 & .012 & 0.250 & .803 & .286 & 3.498 \\
\hline & OnJT & .102 & .053 & .181 & 1.994 & .049 & .208 & 4.803 \\
\hline
\end{tabular}

a. Dependent Variable: ETRP

The P-P of the RSR and the Scatterplot of Model 1 was also used to check the assumption, shows a reasonably straight diagonal line. According to Pallant and Manual (2010), this 
$8^{\text {th }}$ International Conference on Management, Economics and Humanities

7 - 9 December, 2018

Barcelona, Spain

suggests no major deviations from normality. Similarly, in the case of the Scatterplot, most of the scores were concentrated in the center of the plot. This confirms the systematic pattern of the residuals in the model. Hypothesis results of the Model are summarized in Table 7.
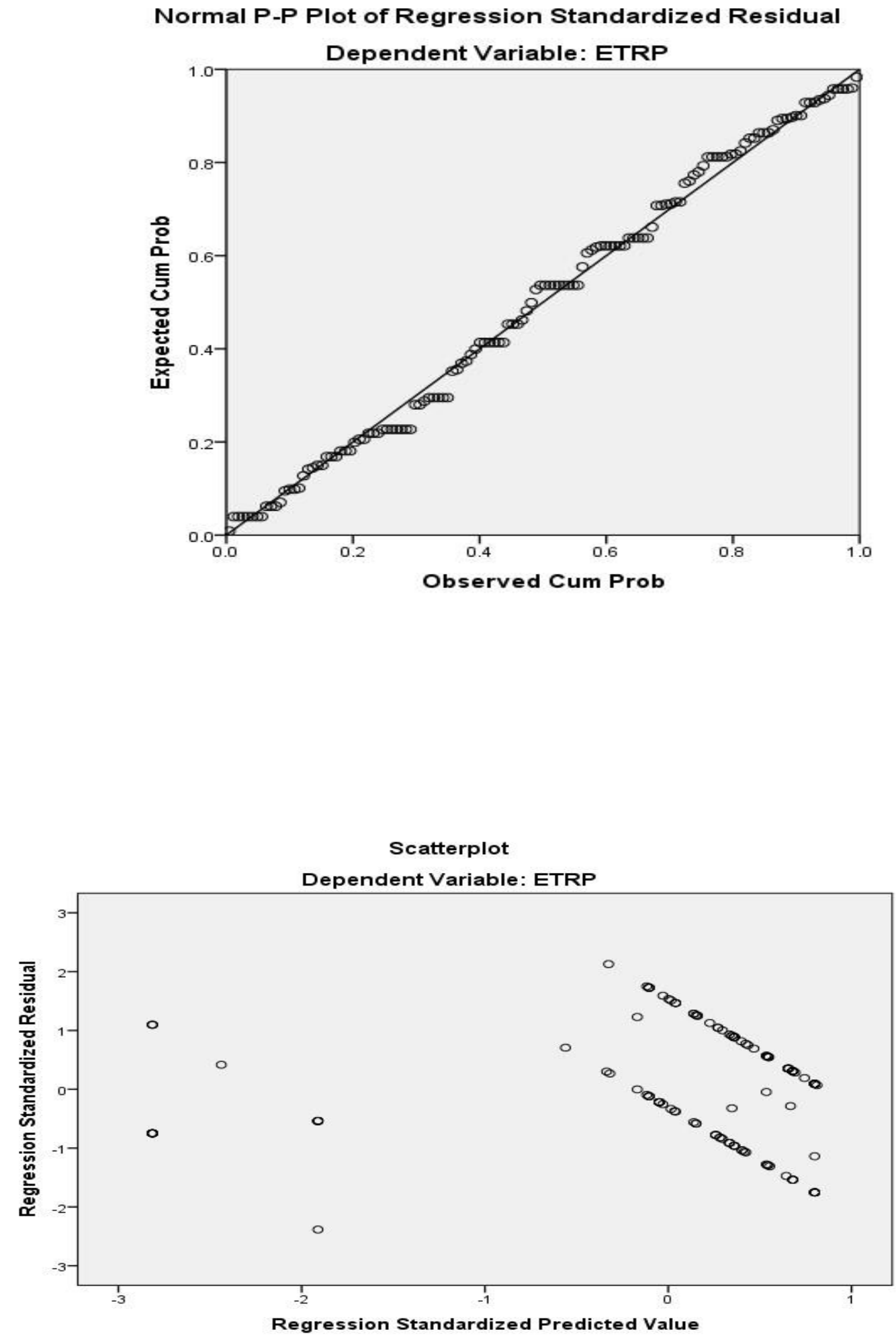
Table 7: Hypothesis results

\begin{tabular}{|c|c|c|}
\hline $\begin{array}{l}\text { Hypotheses } \\
\text { Number }\end{array}$ & Hypothesis Description & $\begin{array}{l}\text { Model } 1 \\
\text { UK }\end{array}$ \\
\hline H1.1.1UK & $\begin{array}{l}\text { Formal training is positively associated with the } \\
\text { employees' turnover rate. }\end{array}$ & Rejected \\
\hline $\mathrm{H} 1.1 .2 \mathrm{UK}$ & $\begin{array}{l}\text { Informal training is positively associated with the } \\
\text { employees' turnover rate. }\end{array}$ & Accepted \\
\hline H1.1.3UK & $\begin{array}{l}\text { General training is positively associated with the } \\
\text { employees' turnover rate. }\end{array}$ & Accepted \\
\hline H1.1.4UK & $\begin{array}{l}\text { Apprenticeship training is positively associated with the } \\
\text { employees' turnover rate. }\end{array}$ & Accepted \\
\hline H1.1.5UK & $\begin{array}{l}\text { Off the job training is positively associated with } \\
\text { employees' turnover rate. }\end{array}$ & Rejected \\
\hline H1.1.6UK & $\begin{array}{l}\text { On the job training is positively associated with } \\
\text { employees' turnover rate. }\end{array}$ & Accepted \\
\hline
\end{tabular}

The provision of training is significantly confirmed that the analysis of models is positively associated with an increase in employees' turnover rates. For example, in the case of the UK, Model 1 see, (Table 7) in the West Midland of demonstrated that that the provision of training (informal, general, apprenticeship, on the job) has been positively associated with an increase in employees' turnover rate within small business manufacturing units. However, the model also demonstrated that there are degrees of formality within the UK environment of heterogeneous is the small business.

According to the analysis, the employee's turnover rate related to the provision of any type of training differentiates between two key elements. The first element is concerned with the small business employees' of internal commitment and approach to the organization. Previous empirical studies within SMEs supported and confirmed (for example) the significant positive relationship between training and employees' commitment of any types which simultaneously the workforce reduce turnover rates. This study is based on the Bakers' (1962) Human Captical Theory (HCT) assumption that a workforce who receive training have higher rates of commitment and this decreases the overall turnover rate of employees. However, in both case analysis revealed that, firms who provided training also faced a high employee turnover rate. With such an observation, both demonstrated models that workforces and small business are more committed to the organization when a visible link see between financial incentives and career progression. Dhar (2015) explains that such incentives (financial and non-financial, training, compensation and benefits) in the workforce lead to retaining and commitment to the organization. However, In the above mention element with the limited financial and non-financial resources, small business owners/managers are seen as reluctant to invest. Is reflected in a high employee turnover rates is the reactive nature of small business management, 
th International Conference on Management, Economics and Humanities 8

which has a negative impact on business performance. This is consistent with previous empirical work that stated that due to the complex nature of small business environments, if the management offers direct or indirect financial or non-financial incentives its can be enhanced the staff commitment (Dalziel, 2010; Nawab and Bhatti, 2011).

The second key element revealed the internal and external labour market issues is related to analysis. In both countries, the labour and capital market are the imperfection key causes of low performance. A skilled workforce is a lack of encourages small business management to invest in training rather compete for human resources. Such type of approach encourages and leads to the poaching of employees. Sufficient empirical evidence supports this argument that conventional internal and external labour market contingencies increase the poaching of employees see, for example, (Ahmed and Chowdhury, 2009; OECD, 2011; Rouditser and McKeown, 2015). This study supports the Spence (1973) MST which mainly focuses on the external marketability of small business employees. As discussed earlier MST and HCT acknowledged the significant positive relationship between both variables. Imperfections in the labour market in both countries encourage small business management to poach skilled workforce. However, Price (1977) argues that training has a negative impact on employees' turnover rate when it moves from low to moderate level within SMEs. Ultimately, the findings from West Midlands confirm that the provision of informal, general, apprenticeship and on the job training leads to an increase in the turnover rate of employees.

\section{Conclusion}

Moreover, in the context of research is the turnover rate of employee's, finding the provision of qualitative and quantitative analysis and confirmed that the training which provides positive outcomes. However, in the labour market of imperfection to unintended lead consequences of poaching and employee's high turnover rate. However, the research suggests that the finding the informal nature due with small business performance, a short period of training increases the employee commitment and loyalty for workforce's. Therefore, small business employees are more concerned with compensation and benefit, career progression of an organization. Therefore a causal of a positive relationship has been identified in the West Midland. (Dhar, 2015; Kennet, 2013) the small business to be more loyal of workforce trends and there is a visible link between small business training, career progression compensation and benefits (Malik and Nilakant, 2011). In addition, in this study findings and suggest that the labour market (qualitative, quantitative) of internal and external issues which also poaching and leads of small business employees within organizations. According to Market Siglling Theory (MST) which proposed by Spence (1973), has the external marketability unintended and effect of human resource training which is increasing the workforce. In this study examine, a workforce skilled prefers themselves and compete for a small business management rather than invest in their training activities. Panagiotakopoulos (2011) according to their research, the labour market and the capital market imperfection to the workforce skilled to encourage the small business management. Small business managers is the cost of training should see as an immediate and lead a threat that could to financial loss is (money) and non-financial loss are (the employees poaching and time activities). Such the research findings are consistent with the behavior model which is presented by Schuler and Jackson (1987).

\section{Practical and Policy Implication of Research}


th International Conference on Management, Economics and

Humanities 8

7 - 9 December, 2018

Barcelona, Spain

The originality of the several actions is this research suggests that the small business management and the policy makers of organizations. These implications suggest several courses of actions for academics, small business organizations, and for the policy makers. The researcher suggests that the small business management should findings and organizing the importance of business performance enhance the employee training. To identify leading training develop and demand to management needs, to develop the training needs of the training programme for their bespoke employees. The research studies that the previous result of the training-performance and the relationship SME confirm that the a positive impact on their business performance organizations will see with any type of training. However, it has been observed that the employee's turnover rate also leads to a training and the employees poaching within the small business units. In this case of result, a systemtic benefit should introduce the system management and the plan of career development to retain the workforce traine. 